\title{
Pembangunan Aplikasi Mobile Hybrid Pada M-Voting Pemilu Raya Universitas Muhammadiyah Malang
}

Hartanto Santoso, Wildan Suharso*, Hariyady

Program Studi Teknik Informatika, Fakultas Teknik, Universitas Muhammadiyah Malang

*Email: wsuharso@umm.ac.id

Info Artikel

Kata Kunci :

Aplikasi M-voting, User centered design. Front end, System usabiltiy scale, Flutter.

\section{Keywords :}

M-voting application, User centered design, Front end, System usability scale, Flutter.

\section{Tanggal Artikel}

Dikirim : 24 maret 2020

Direvisi : 18 Mei 2020

Diterima : 25 Mei 2020

\begin{abstract}
Abstrak
Voting merupakan pemilihan suara terbanyak yang bertujuan untuk mencari suatu kesepakatan bersama terhadap sesuatu yang penting. Pada penelitian ini bertujuan membangun frontend aplikasi m-voting untuk pemilu raya di Universitas Muhammadiyah Malang. Penelitian ini menggunakan metode User Centered Design (UCD), metode ini berfokus pada pengguna sebagai pusat dalam pengembagan aplikasi. Pada pembangunan aplikasi ini menggunakan framework flutter. Flutter merupakan framework yang dibuat google menggunakan bahasa dart. Flutter bersifat cross platform, dimana pengembagan menggunakan framework ini dapat membuat satu aplikasi yang dapat berjalan di dua sistem operasi baik iOs dan android. Sedangkan untuk pengujian pada pembangunan frontend aplikasi M-voting ini menggunakan System Usability Scale (SUS). Skor yang didapatkan setelah pengujian sebesar 71,61 yang berdasarkan interpretasi menggunakan rating SUS score berada pada tingkat 'Good'.
\end{abstract}

\begin{abstract}
Abstarct
Voting is the most votes cast offered to seek mutual agreement on something important. In this study, trying to build m-voting applications for the general election at the University of Muhammadiyah Malang. This study uses the User Centered Design (UCD) method, this method uses the user as the center in the development application. In developing this application using the framework flutter. Flutter is a framework created by Google using the dart language. Active cross platform flutter, where developers using this framework can create one application that can run on two operating systems both iOS and Android. As for testing on the frontend development of this Mvoting application using System Usability Scale (SUS). The score obtained after testing was 71.61 based on interpretation using the SUS rating score depending on the level of 'Good'
\end{abstract}

\section{PENDAHULUAN}

Indonesia merupakan salah satu negara di dunia yang menganut sistem politik demokrasi yang dalam penerapannya menginginkan partisipasi politik yang seluas-luasnya kepada seluruh masyarakat untuk ikut berperan aktif dalam menentukan arah pembangunan Bangsa. Khususnya mahasiswa yang merupakan bagian dari masyarakat indonesia yang mempunyai kontribusi besar bagi negara karena nantinya akan menjadi penerus dari bangsa ini. Salah satu perannya yaitu dengan menentukan pemimpin secara langsung umum, bebas, dan rahasia melalui sebuah pemilihan umum[1]. Biasanya dalam suatu pemilihan dilakukan dengan secara langsung yaitu dengan dating ke tempat pemilihan yang sudah ditentukan. Seiring dengan berkembangnya teknologi maka pemilihan mulai dilakukan menggunakan teknologi yaitu aplikasi M-voting. Namun menghasilkan suatu fitur-fitur aplikasi M-voting yang berfolus pada pengguna merupakan suatu tantangan tersendiri.

M-Voting merupakan kepanjangan dari Mobile Voting. M-voting adalah pemungutan suara dimana semua data dicatat, disimpan, dan diproses dalam bentuk informasi digital[2]. Pembangunan M-voting ini dibuat agar mempermudah dan meningkatkan kesadaran mahasiswa dalam menggunakan hak suaranya. Kesadaran politik di 
lingkungan kampus akan memunculkan peran aktif mahasiswa dalam meningkatkan mutu kehidupan kampus dan diharapkan akan memunculkan kebijakan yang dikeluarkan nantinya bermanfaat untuk seluruh mahasiswa. Namun, kesadaran mahasiswa di Universitas Muhammadiyah Malang dalam Pemira untuk memilih pemimpin masih cenderung rendah. Selama ini Pemira di Universitas Muhammadiyah Malang masih dilakukan secara konvensional. Hal ini dapat dilihat dari data kuesioner yang sudah disebarkan dimana didapatkan hasil 65,7\% sistem pemira secara konvensional masih belum memudahkan bagi mahasiswa. Dari permasalahan tersebut maka diperlukan aplikasi yang mengatasi masalah tersebut agar mahasiswa ikut berpartisipasi untuk memberikan hak suaranya. Berdasarkan data hasil kuesioner yang sudah disebarkan didapatkan $51,4 \%$ sangat setuju, 37,1\% setuju, 8,6\% tidak setuju dan sangat tidak setuju kosong artinya pembangunan aplikasi sangat dibutuhkan sekali untuk memudahkan mahasiswa dalam melakukan pemilihan di Pemira Maka pada penelitian ini dirancang aplikasi yang memudahkan mahasiswa agar memberikan hak suaranya menggunakan aplikasi android yaitu M-voting. Android merupakan sistem operasi perangkat lunak mobile berbasis linux. Perancangan aplikasi berbasis android ini dipilih karena bersifat mobile dan banyak pengguna sehingga cocok sekali[3]. Pembuatan aplikasi pada smartphone dibuat dengan Flutter framework. Flutter framework adalah sebuah SDK (Software Development Kit) yang dibuat oleh Google untuk membangun aplikasi yang yang bersifat hybrid[4].

Pada penelitian terdahulu dengan judul "Aplikasi Hybrid pada Sistem Informasi Penyewaan Buku". Penelitian ini menjelaskan pemanfaatan teknologi mobile hybrid sebagai solusi untuk membanguan aplikasi mobile hybrid pada sisi klien sistem informasi penyewaan buku menggunakan framework lonic. Keuntungan utama menggunakan menggunakan aplikasi hybrid adalah kemampuannya untuk menjalankan source code dalalm berbagai platform[5]. Hybrid juga memiliki perilaku seperti aplikasi native. Kelebihan lainnya menggunakan teknologi hybrid yaitu proses loading cepat dan dapat dijalankan sepenuhnya secara offline seperti native[6].

Hasil dan tujuan penggunaaan teknologi hybrid adalah pilihan yang tepat untuk pembangunan aplikasi Mvoting karena dengan penggunaan teknologi hybrid mengatasi penggunaan di berbagai platform smartphone supaya nantinya aplikasi ini akan mempermudah mahasiswa dalam melakukan pemilihan calon kandidat untuk mengisi tampuk kepemimpinan di organisasi intra di Universitas Muhammadiyah Malang selanjutnya menjadi lebih efisien dan efektif. Dengan tujuan dan hasil tersebut maka akan diterapkan metode UCD untuk melibatkan calon pengguna pada tahap awal pengembangan sehingga calon pengguna memberikan masukan mengenai antarmuka aplikasi serta hasil akhir dalam membangun aplikasi ini diharapkan menghasilkan tampilan dan fungsionalitas yang maksimal serta memiliki nilai ketergunaan.

\section{METODE PENELITIAN}

User Centered Design adalah sebuah filosofi perancangan yang menempatkan pengguna sebagai pusat dari sebuah proses pengembangan sistem. Pendekatan User Centered Design akan melibatkan pengguna pada proses pengembangan sehingga pengguna dapat memberikan saran mengenai antarmuka aplikasi, serta hasil akhir dalam perancangan aplikasi ini diharapkan menghasilkan desain solusi sesuai dengan kebutuhan pengguna[7]. Dengan memanfaatkan pendapat pengguna, serta pola dan tingkah laku pengguna. Tujuan penggunaan metode User Centered Design ini adalah untuk mengatasi masalah ketidakmampuan pengguna dalam menggunakan sistem dan diharapkan mampu mengetahui fungsi sistem dengan hanya sekali pakai. Pengguna merupakan pusat pengembangan sistem dan perilaku pengembangan sistem didasarkan pada pengguna[8]. Oleh karena itu, agar tercapainya tujuan itu digunakan metode UCD yang akan melibatkan pengguna dalam proses pengembangan.

Pada penelitian ini terdapat empat tahap pengembangan yang dapat dilihat pada gambar 1. Tahapan pengmebangan menggunakan metode UCD antara lain specify the context of user, specify user and organizational requirements, produce design solution, dan evaluate designs against user requirements. Berikut penjelasan dari tahapan-tahapan pada metode UCD [9]:

\subsection{Specity the Context of User}

Mengidentifikasi orang yang akan menggunakan sistem. Ini akan menjelaskan untuk apa dan dalam kondisi seperti apa, mereka akan menggunakan sistem. 


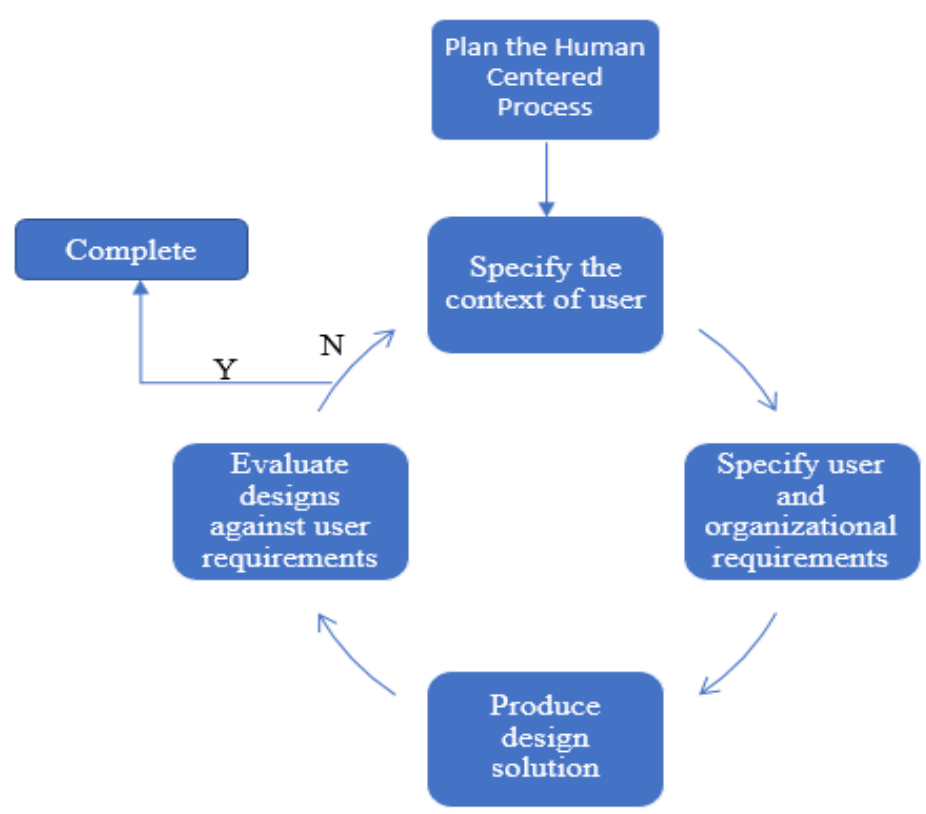

Gambar 1. Metode penelitian [10]

\subsection{Specify User and Organizational Requirements}

Mengidentifikasi kebutuhan pengguna dan kebutuhan organisasi. Dalam metode UCD, peneliti memperluas aktivitas kebutuhan fungsional sistem dengan membuat pernyataan eksplisit kebutuhan pengguna dan organisasi, dalam hubungannya dengan konteks deskripsi penggunaan dalam kualitas perancangan interaksi manusia dan komputer, kualitas, dan isi sistem untuk meningkatkan kinerja yang efektif untuk pengguna, dan kerjasama dan komunikasi yang efektif di antara pengguna dan personil pengembang sistem.

\subsection{Produce Designs Solution}

Membangun desain sebagai solusi dari sistem yang sedang dianalisis. Untuk perancangan sistem peneliti membuat use case diagram, activity diagram, dan sequence diagram untuk membantu analisa sistem.

\subsection{Evaluate Designs against User Requirements}

Melakukan evaluasi terhadap desain yang dilakukan pada tahap sebelumnya. Hal ini dilakukan untuk memastikan tujuan pengguna dan organisas tercapai atau belum. Tahap evaluasi merupakan tahap terakhir dalam pembuatan suatu aplikasi. Pada proses ini harus disiapkan fasilitas untuk mendapatkan umpan balik dari aplikasi yang dibuat yang diperlukan untuk memperbaiki rancangan.

\section{HASIL DAN PEMBAHASAN}

\subsection{Use Case Diagram}




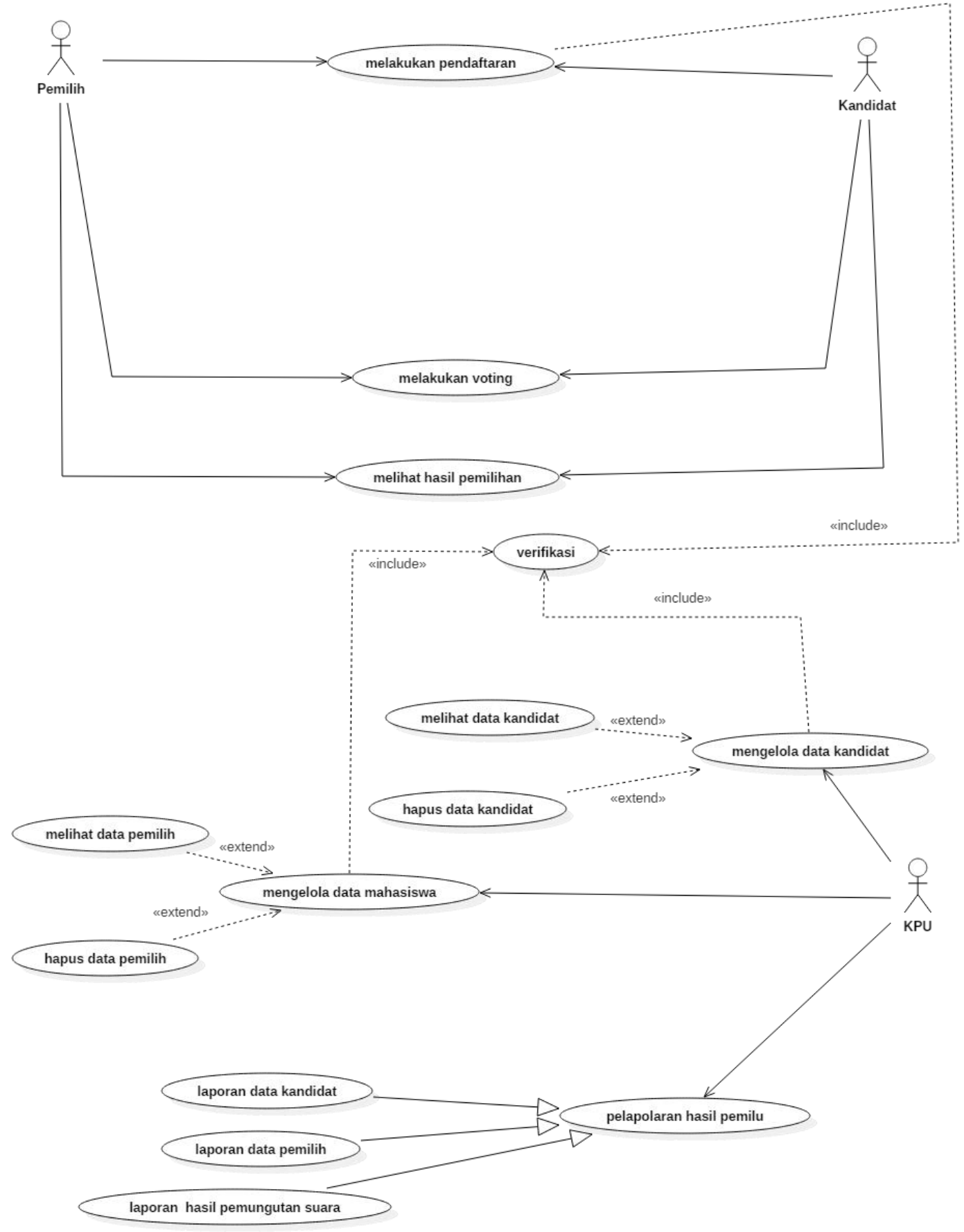

Gambar 1. Use Case Diagram

\subsection{Hasil Implementasi}

Gambar berikut ini merupakan halaman splash screen. Halaman ini merupakan halaman pertama aplikasi sebelum masuk ke menu utama. Halaman berfungsi sebagai pegenal bahwa aplikasi ini bernama M-voting UMM. 


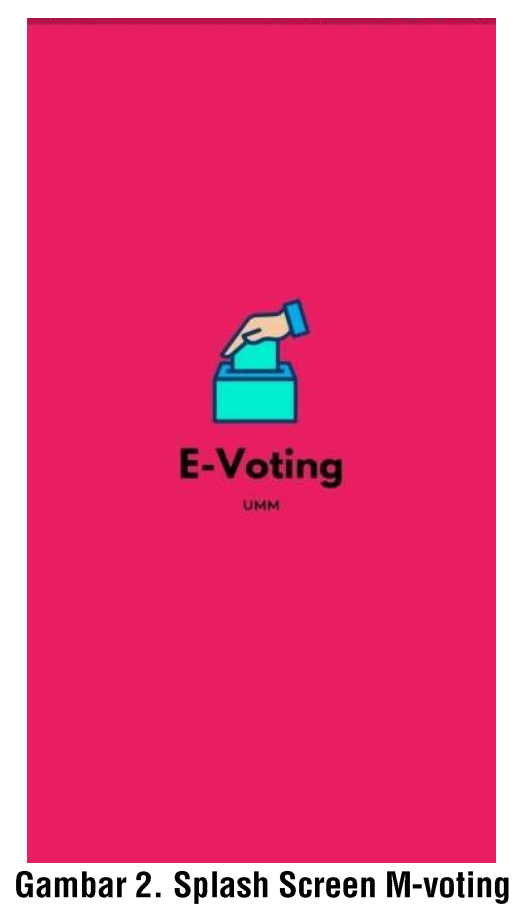

Halaman login merupakan halaman untuk pengguna untuk masuk ke halaman aplikasi. Pada halaman ini pengguna diminta memasukkan NIM dan password.

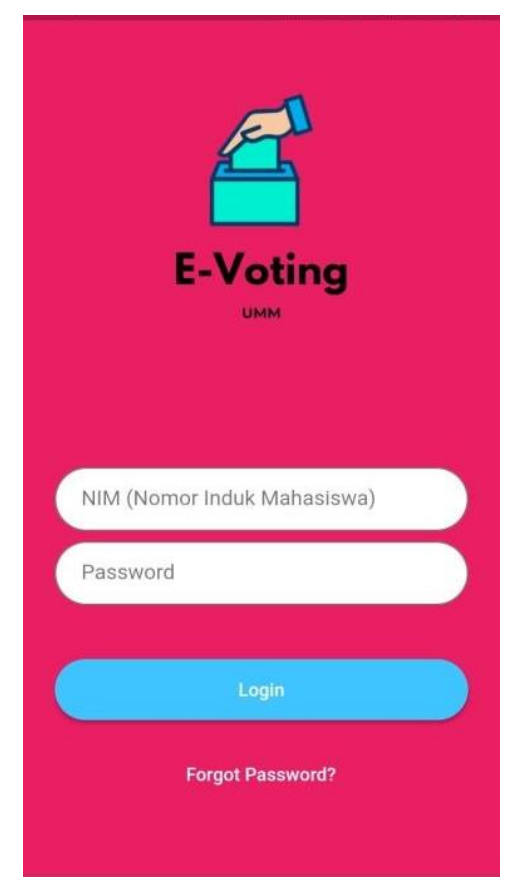

\section{Gambar 3. Login M-voting}

Pada halaman reset ini digunakan ketika pengguna lupa password untuk masuk ke aplikasi. Halaman ini meminta pengguna memasukkan e-mail. Setelah pengguna memasukkan e-mail maka pengguna akan dikirim pesan untuk memasukkan password baru. 


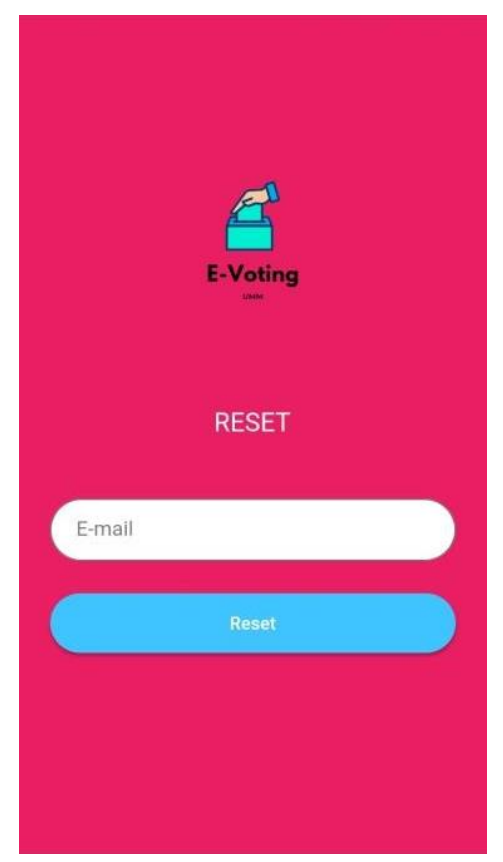

\section{Gambar 4. Reset password M-voting}

Halaman kategori kandidat merupakan tampilan awal ketika pengguna membuka aplikasi. Pada tampilan ini menampilan kategori organisasi antara lain BEMU (Badan Eksekutif Mahasiswa tingkat universitas), BEMFA (Badan Eksekutif Mahasiswa tingkat Fakultas), SEMU (Senat Mahasiswa tingkat Universitas), SEFA (Senat Mahasiswa Tingkat Fakultas), dan HMJ (Himpunan Mahasiswa Jurusan).

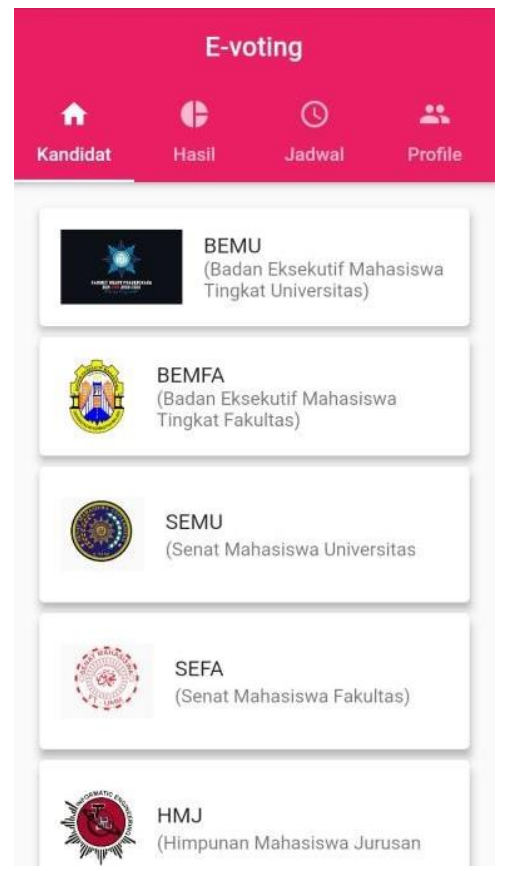

\section{Gambar 5. Menu List Kategori Kandidat}

Halaman list kandidat merupakan halaman yang menampilkan kandidat yang dicalonkan. Halaman ini ditampilkan ketika pengguna memilih salah satu dari list kategori di menu kandidat. 


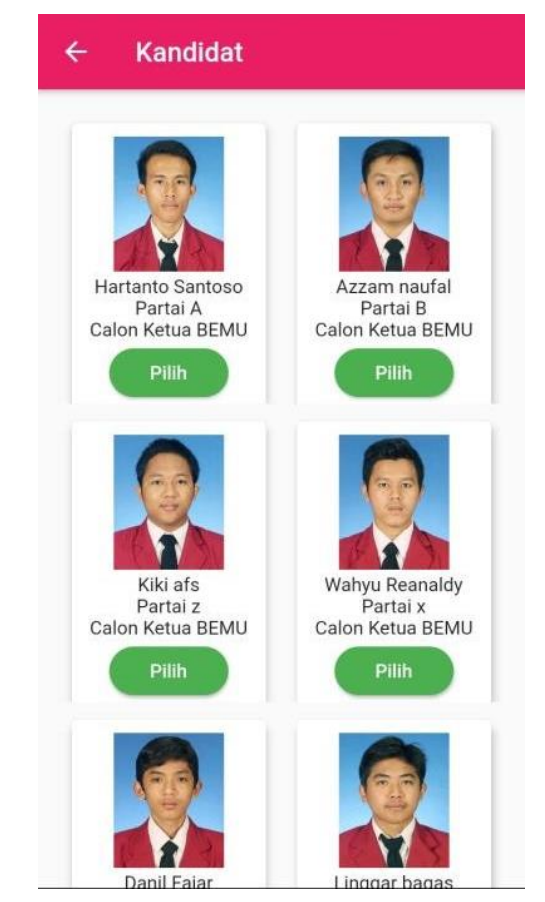

\section{Gambar 6. Menu Detail List Kandidat}

Halaman list kategori hasil merupakan tampilan awal menu hasil. Pada tampilan ini menampilan kategori organisasi antara lain BEMU(Badan Eksekutif Mahasiswa tingkat universitas), BEMFA(Badan Eksekutif Mahasiswa tingkat Fakultas), SEMU(Senat Mahasiswa tingkat Universitas), SEFA(Senat Mahasiswa Tingkat Fakultas), dan HMJ(Himpunan Mahasiswa Jurusan).

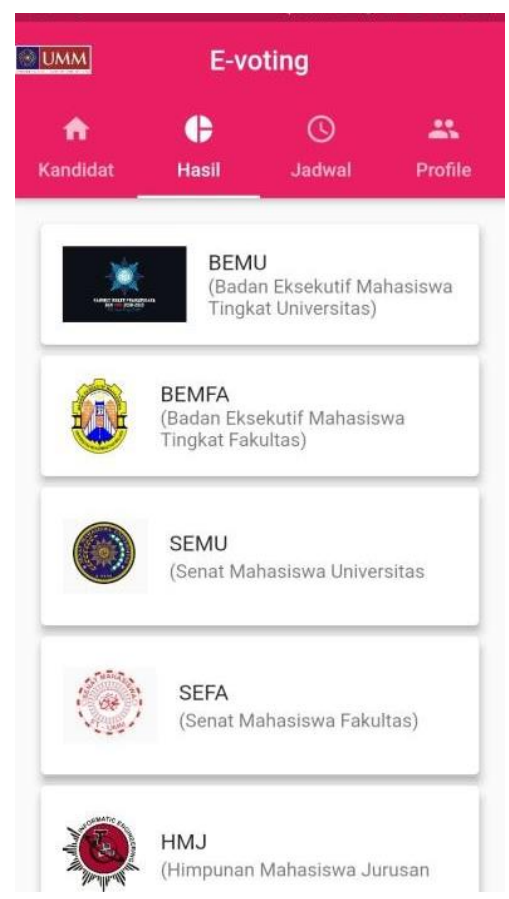

Gambar 7. Menu Hasil

Halaman list hasil merupakan halaman yang menampilkan hasil dari pemilihan kandidat calon dari masingmasing organisasi. 


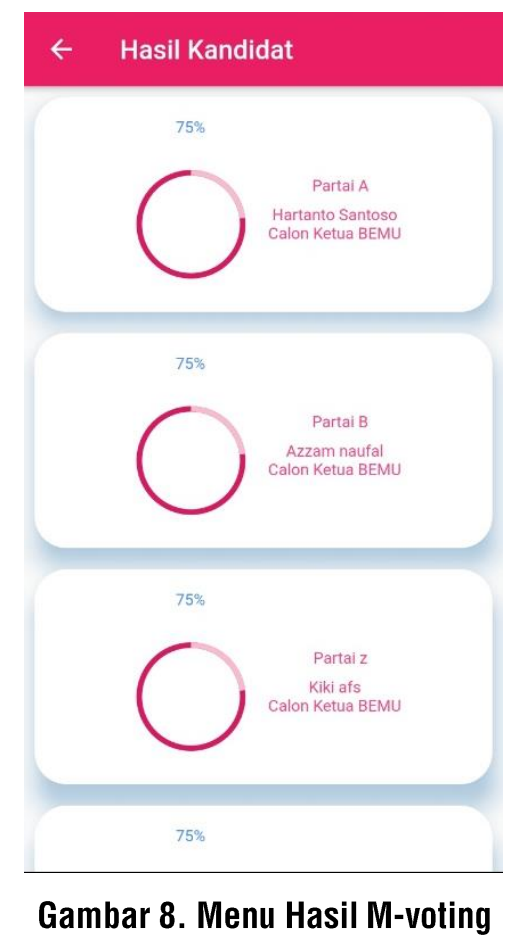

Halaman jadwal merupakan halaman yang menampilakan jadwal tentang pemilu raya di Universitas Muhammadiyah Malang di aplikasi M-voting. Halaman ini menampilkan antara lain jadwal kampanye, jadwal pencoblosan, dan jadwal pengumuman.
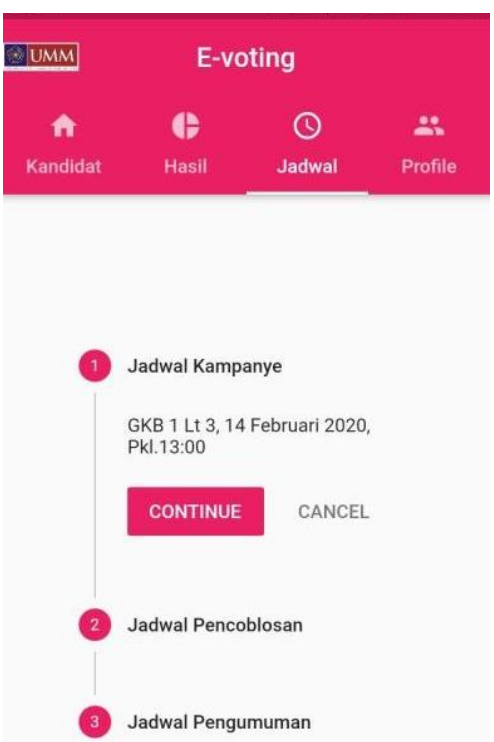

\section{Gambar 9. Menu Jadwal M-voting}

Halaman profile merupakan halaman yang menampilkan informasi mengenai pengguna aplikasi. Ketika pengguna login menggunakan NIM dan password maka pengguna dapat melihat informasi personalnya pada menu profile di aplikasi M-voting. 

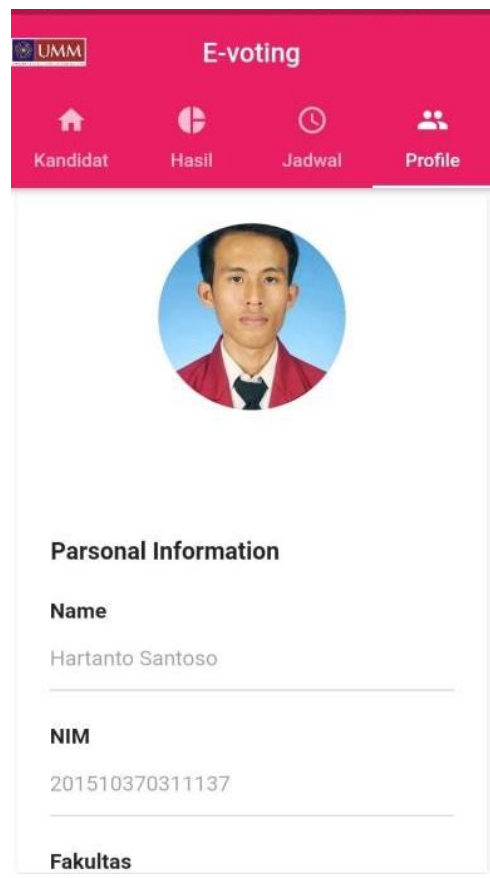

\section{Gambar 10. Menu Profil M-voting}

\subsection{Pengujian Aplikasi}

Pengujian pada frontend aplikasi M-voting ini menggunakan System Usability Scale (SUS) yang berbentuk kuesioner. Pengujian ini bertujuan untuk mengetahuai persepsi pengguna terhadap kesesuain aplikasi yang dibuat. Jumlah responden yang digunakan berjumlah 30 responden. Kuesioner yang mengisi ditujukan untuk mahasiswa Universitas Muhammadiyah Malang. Hal ini dilakukan karena aplikasi ini dibuat nantinya untuk mahasiswa Universitas Muhammadiyah Malang.

Tabel 1 Tabel Rangkuman Hasil Kuesioner SUS

\begin{tabular}{lcccccccccccc}
\hline \multirow{2}{*}{ Responden } & $\mathbf{1}$ & $\mathbf{2}$ & $\mathbf{3}$ & $\mathbf{4}$ & $\mathbf{5}$ & $\mathbf{6}$ & $\mathbf{7}$ & $\mathbf{8}$ & $\mathbf{9}$ & $\mathbf{1 0}$ & Jumlah & Skor SUS \\
\hline Responden 1 & 3 & 3 & 4 & 1 & 3 & 3 & 3 & 3 & 3 & 3 & 29 & 72,5 \\
\hline Responden 2 & 4 & 1 & 4 & 1 & 3 & 3 & 3 & 3 & 3 & 2 & 27 & 67,5 \\
\hline Responden 3 & 3 & 2 & 3 & 1 & 3 & 3 & 3 & 3 & 3 & 1 & 25 & 62,5 \\
\hline Responden 4 & 4 & 3 & 3 & 3 & 3 & 3 & 3 & 3 & 3 & 0 & 28 & 70 \\
\hline Responden 5 & 3 & 2 & 3 & 1 & 3 & 2 & 3 & 2 & 3 & 2 & 24 & 60 \\
\hline Responden 6 & 4 & 1 & 4 & 3 & 3 & 3 & 4 & 3 & 3 & 4 & 32 & 80 \\
\hline Responden 7 & 3 & 1 & 3 & 3 & 3 & 2 & 3 & 3 & 3 & 3 & 27 & 67,5 \\
\hline Responden 8 & 4 & 3 & 4 & 0 & 4 & 2 & 1 & 1 & 3 & 1 & 23 & 57,5 \\
\hline Responden 9 & 4 & 3 & 4 & 0 & 4 & 4 & 4 & 4 & 4 & 1 & 32 & 80 \\
\hline Responden 10 & 4 & 3 & 3 & 0 & 2 & 0 & 3 & 0 & 1 & 1 & 17 & 42,5 \\
\hline Responden 11 & 4 & 3 & 3 & 3 & 4 & 4 & 3 & 4 & 3 & 1 & 32 & 80 \\
\hline Responden 12 & 4 & 3 & 4 & 1 & 2 & 3 & 3 & 3 & 3 & 0 & 26 & 65 \\
\hline Responden 13 & 4 & 3 & 3 & 4 & 4 & 3 & 3 & 4 & 4 & 4 & 36 & 90 \\
\hline Responden 14 & 4 & 4 & 3 & 4 & 4 & 4 & 4 & 4 & 3 & 4 & 38 & 95 \\
\hline Responden 15 & 4 & 3 & 3 & 4 & 4 & 4 & 4 & 4 & 4 & 3 & 37 & 92,5 \\
\hline Responden 16 & 4 & 3 & 4 & 3 & 4 & 3 & 3 & 3 & 4 & 3 & 34 & 85 \\
\hline Responden 17 & 4 & 3 & 4 & 4 & 4 & 3 & 4 & 0 & 4 & 3 & 33 & 82,5 \\
\hline Responden 18 & 4 & 0 & 3 & 1 & 4 & 2 & 3 & 3 & 3 & 3 & 26 & 65 \\
\hline Responden 19 & 4 & 3 & 3 & 1 & 4 & 1 & 3 & 3 & 3 & 3 & 28 & 70 \\
\hline Responden 20 & 4 & 3 & 4 & 3 & 3 & 1 & 4 & 2 & 3 & 1 & 28 & 70 \\
\hline Responden 21 & 4 & 1 & 4 & 4 & 4 & 3 & 4 & 4 & 4 & 3 & 35 & 87,5 \\
\hline
\end{tabular}




\begin{tabular}{|c|c|c|c|c|c|c|c|c|c|c|c|c|}
\hline \multirow{2}{*}{ Responden } & \multicolumn{10}{|c|}{ Skor Pernyataan SUS } & \multirow{2}{*}{$\begin{array}{c}\text { Jumlah } \\
\text { Skor }\end{array}$} & \multirow[t]{2}{*}{ Skor SUS } \\
\hline & 1 & 2 & 3 & 4 & 5 & 6 & 7 & 8 & 9 & 10 & & \\
\hline Responden 22 & 4 & 2 & 4 & 3 & 3 & 2 & 3 & 3 & 3 & 3 & 30 & 75 \\
\hline Responden 23 & 3 & 1 & 4 & 2 & 3 & 2 & 4 & 4 & 3 & 4 & 30 & 75 \\
\hline Responden 24 & 3 & 1 & 3 & 3 & 4 & 0 & 3 & 3 & 3 & 2 & 25 & 62,5 \\
\hline Responden 25 & 3 & 1 & 3 & 3 & 4 & 2 & 3 & 3 & 3 & 2 & 27 & 67,5 \\
\hline Responden 26 & 3 & 0 & 3 & 2 & 3 & 2 & 3 & 3 & 3 & 2 & 24 & 60 \\
\hline Responden 27 & 3 & 0 & 3 & 2 & 3 & 2 & 3 & 3 & 3 & 2 & 24 & 60 \\
\hline Responden 28 & 3 & 1 & 4 & 3 & 4 & 2 & 4 & 4 & 3 & 2 & 30 & 75 \\
\hline Responden 29 & 4 & 1 & 3 & 3 & 3 & 3 & 3 & 3 & 2 & 3 & 28 & 70 \\
\hline Responden 30 & 4 & 1 & 3 & 1 & 4 & 3 & 2 & 3 & 3 & 1 & 25 & 62,5 \\
\hline Responden 31 & 3 & 1 & 3 & 3 & 3 & 3 & 3 & 3 & 3 & 3 & 28 & 70 \\
\hline \multicolumn{12}{|c|}{ Jumlah } & 2220 \\
\hline
\end{tabular}

Setelah skor SUS didapatkan dari seluruh responden selanjutnya skor dijumlahkan kemudian diambil rata-ratanya menggunakan persamaan berikut :

$$
\bar{x}=\frac{\sum x}{n}=\frac{2220}{31}=71,61
$$

Keterangan :

$$
\begin{array}{ll}
\bar{x} & =\text { skor rata-rata } \\
\sum x & =\text { jumlah skor SUS } \\
n & =\text { jumlah responden }
\end{array}
$$

Berdasarkan pengujian pada aplikasi M-voting yang dilakukan pada 31 responden didapatkan rata-rata skor SUS 71,61. Berdasarkan System Usabilitiy Scale (SUS), skor yang didapatkan dari hasil pengujian aplikasi Mvoting UMM terdapat pada posisi dengan peringkat GOOD.

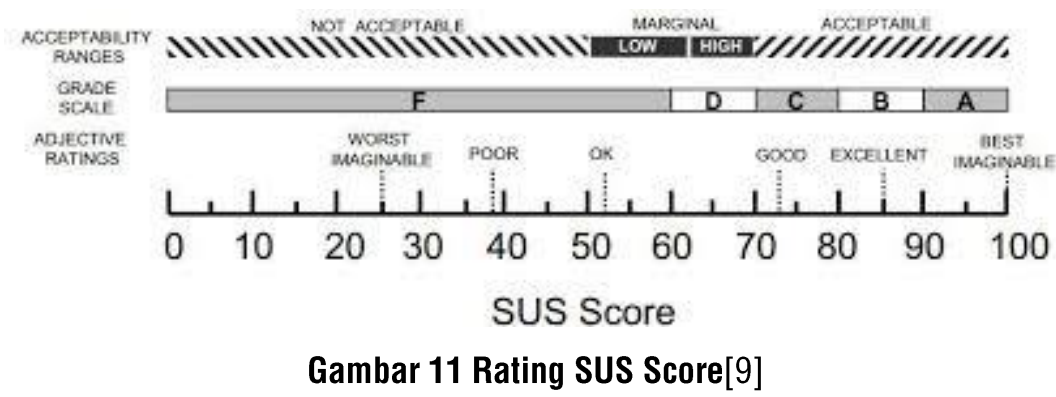

\section{KESIMPULAN}

Kesimpulan pada penelitian ini yaitu bahwa pembangunana front-end aplikasi M-voting UMM ini berhasil. Fitur yang terdapat pada aplikasi M-voting UMM ini antara lain fitur kandidat,fitur hasil, fitur jadwal, dan fitur profile. Aplikasi ini dibuat menggunakan framework flutter. Pengujian pada aplikasi M-voting UMM ini menggunakan metode SUS yang dimana dihasilkan skor 71,61 yang berdasarkan interpretasi menggunakan rating SUS score pada gambar 11 berada pada tingkat 'Good'. 


\section{DAFTAR PUSTAKA}

[1] petrus gleko, "Strategi komisi pemilihan umum dalam upaya meningkatkan partisipasi politik masyarakat pada pemilihan umum kepala daerah," vol. 6, no. 1, pp. 38-47, 2017.

[2] R. Prananda, H. Anra, and H. S. Pratiwi, "Rancang Bangun Aplikasi E-Voting Berbasis Android (Studi Kasus : Pemilihan Ketua Organiasi di Lingkungan Fakultas Teknik Universitas Tanjungpura)," J. Sist. dan Teknol. Inf., vol. 5, no. 1, pp. 17-21, 2017.

[3] R. A. D. Studi and K. Sman, "APLIKASI MOBILE VOTING BERBASIS ANDROID UNTUK PEMILIHAN KETUA OSIS DENGAN MODEL RAD STUDI KASUS SMAN 1 PARUNGKUDA," vol. 6, no. 2, pp. 139-142, 2018.

[4] P. Himawan, "Mengenal Flutter pada Mobile Apps Development Android dan iOS," Crocodic, 2018. [Online]. Available: http://crocodic.com/mengenal-flutter-pada-mobile-apps-development-android-dan-ios/. [Accessed: 10-Sep-2019].

[5] D. I. Pradana and I. Waspada, "Aplikasi Hybrid Pada Sistem Informasi Penyewaan Buku," Simetris J. Tek. Mesin, Elektro dan IImu Komput., vol. 10, no. 1, pp. 1-14, 2019.

[6] G. W. W. Granodio Daegal Wibowo, Wildan Suharso, "Perancangan Kuisioner Evaluasi Mutu Berbasis Mobile Web Application Menggunakan PWA (Progressive Web App)(Studi Kasus: simutu. umm. ac. id)," 2017.

[7] D. Pratiwi, M. C. Saputra, and N. H. Wardani, "Penggunaan Metode User Centered Design ( UCD ) dalam Perancangan Ulang Web Portal Jurusan Psikologi FISIP Universitas Brawijaya," vol. 2, no. 7, pp. 24482458, 2018.

[8] M. Rohandi, N. Husain, and I. W. Bay, "Pengembangan Mobile-Assisted Language Learning Menggunakan User Centered Design," vol. 7, no. 1, 2018.

[9] I. Print et al., "Jurnal Teknologi dan Sistem Informasi Penerapan Metode UCD ( User Centered Design ) pada E-Commerce Putri Intan Shop Berbasis Web," vol. 02, pp. 269-278, 2017.

[10] A. Krisnoanto, A. H. Brata, and M. T. Ananta, "Penerapan Metode User Centered Design Pada Aplikasi ELearning Berbasis Android ( Studi Kasus : SMAN 3 Sidoarjo ),” vol. 2, no. 12, pp. 6495-6501, 2018. 